\title{
Applying sustainability techniques in eco-industrial parks
}

\author{
C. de Sousa Silva ${ }^{1}$, L. Lackóová ${ }^{2} \&$ T. Panagopoulos ${ }^{1}$ \\ ${ }^{1}$ University of Algarve, Portugal, \\ ${ }^{2}$ Faculty of Horticulture and Landscape Engineering, \\ Slovak University of Agriculture in Nitra, Slovakia
}

\begin{abstract}
A sustainable city is designed with consideration on social wellbeing and follows the concept of a circular economy creating the smallest possible ecological footprint and giving emphasis on natural capital restoration and climate change adaptation and mitigation. The aim of an eco-industrial park is to improve the economic performance of the stakeholders while minimizing environmental impact. This feasibility study proposes a formal and aesthetic solution that respects the spirit of place, landscape integration of the infrastructures and demonstrates sustainability techniques in a conceptual level Master Plan of the new industrial park of Tavira. It proposes a multi-modal transportation system solution to decrease the distance travelled by vehicles and coexistence with pedestrian and bicycle traffic. It promotes green infrastructure interconnected with the hinterland green areas and mixed-use multifunctional landscapes. It endorses a decrease in impervious surfaces in car parking and enhances efforts to reduce energy use adopting renewable energy lighting solutions and urban allotments and greenroofs/walls using native vegetation to decrease heat island effects. It recommends compactness of the urbanized areas to save soil and facilitate the integration in the environment. Sustainable landscape design in industrial environment may guarantee quality and prestige living environment.
\end{abstract}

Keywords: sustainable city, industrial park, landscape integration, green infrastructure. 


\section{Introduction}

An industrial park is defined as "land sub-divided and developed for the use of several firms simultaneously, distinguished by its shareable infrastructure and close proximity of firms" [1]. An eco-industrial park (EIP) involves a network of stakeholder organizations, working together to improve their environmental and economic performance. Some planners use the term "industrial ecosystem" to describe the type of symbiotic relationships that develop amongst participating stakeholders. According to Côté and Hall [2] an EIP is an industrial system which conserves natural and economic resources; reduces production, material, energy; improves operating efficiency, quality of life worker health and public image; and provides income from wasted materials. The goal of an EIP is to improve the economic performance of the stakeholders while minimizing environmental impact [3].

A sustainable city is designed with consideration of environmental impact, minimization of required inputs of energy, water and food, and outputs of waste, heat and pollution and create the smallest possible ecological footprint [4]. Industrial ecology give emphasis on natural capital restoration and focuses on social wellbeing. Sustainable urban development seeks a holistic understanding of urban environmental quality and human well-being [5].

Sustainable urban development should be guided by a planning vision that promotes green infrastructure interconnected with the hinterland green areas, multi-modal transportation system, and mixed-use multifunctional landscapes [6, 7]. Global climate change has made sustainability more urgent and forced planning to be more focused in the long-term goals enhancing efforts to reduce energy use, distance traveled by vehicles, impervious surfaces and heat island effects.

Sustainable cities must be simultaneously economically viable, socially just, politically well managed and ecologically sustainable to maximize human comfort [5]. Most cities attempting to move toward sustainability need to include an industrial sector in their economic mix, nevertheless with fundamental improvements in industrial environmental performance, resource efficiency and landscape integration into their host community. EMPET, the company that is managing the industrial park of Tavira, Portugal and the local municipality are willing to make a step forward and adapt their industrial space in the new era in which the three pillars of sustainability (economic, social and environmental) are of major importance. Sustainability techniques are mostly living solutions that are inspired and supported by nature, which simultaneously provide environmental, social and economic benefits and help build resilience [8].

For that purpose, the aim of this paper is to demonstrate sustainability techniques at the new industrial park of Tavira, proposing landscape integration of the infrastructures in a conceptual level Master Plan and feasibility study. 


\section{Materials and methods}

\subsection{Study area}

The Santa Margarida industrial park (Fig. 1) is located in a rural area in the County of Tavira. This industrial park covers a total area of 26ha, with 5 plots of preexisting habitations, 145 plots for industry or storage, 8 plots for shops and services, a sewage treatment station, an ecocentre, a service station and a restaurant.
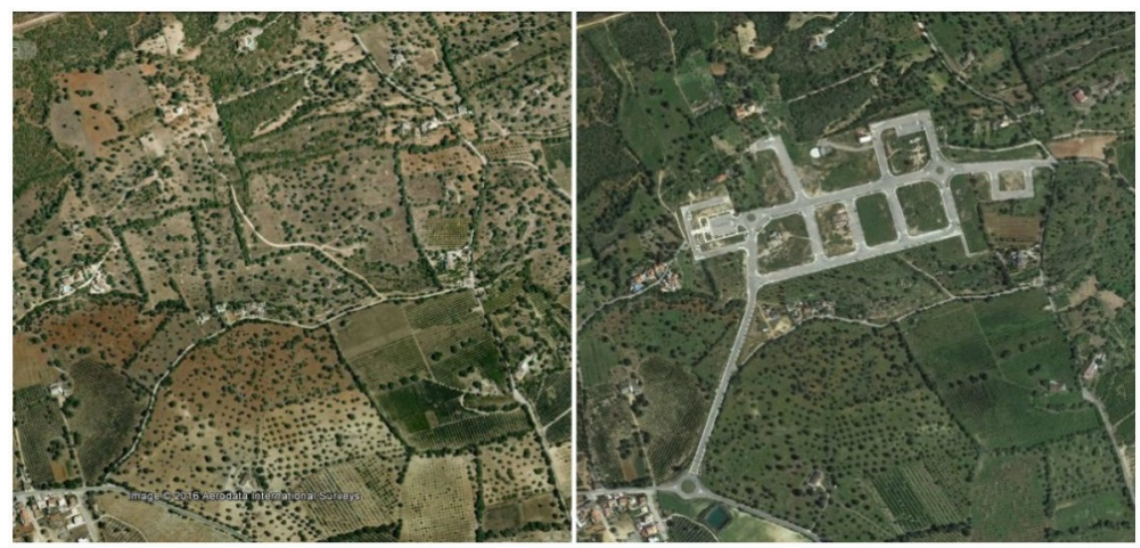

Figure 1: Before and after the implementation of Santa Margarida Industrial Park (images from Google Earth, 2007 and 2013).

The climate of the study area presents cool and slightly rainy winters and hot and dry summers. The average of the temperature variation is not significant because of the sea proximity. The soils present typical reddish characteristics of the barrocal, called terra rossa. The majority of this type of soil is very favorable to agriculture. Before the intervention (Fig. 1), this area was characterized by the presence of native plants such as Chamaerops humilis, Myrtus communis, Pistacia lentiscus, Quercus coccifera, and some native trees, for example, Olea europaea, Prunus dulcis, Ceratonia siliqua. In general, the quality of landscape was medium to high due to the presence of farmlands, very characteristics in the Algarve landscape [9].

The local social economy is characterized by shrinking population and the first signs of aging population [10]. According to the Environmental Impact Assessment study [9] before the Industrial Park construction, the area of implantation presented high unemployment rate, abandonment of rural agricultural activities and was sparsely populated, where only 19 persons reside. Most of the companies in Tavira city are from commercial, construction, agricultural, forestry, hunting and fishing, restaurants and hotels sectors. The industrial sector was not significant and was dispersed over the Tavira municipality, often located close to the residential areas. 


\subsection{Guidelines for landscape integration of new industrial sites}

According to Buch [11] industrial space planning should have a global and uniform treatment. Important steps to achieve landscape integration are the following. As it is an inherent requirement of any project a systematic analysis of the site should be done at first (morphology, structure, key elements, components, visual, etc.). Each site is unique and it is imperative to identify its character or genius loci. Therefore, what is different and unique is an added value during the conception phase of the project when the integration strategy is chosen. The perceptual aspects and the social image of the site are accessed through existing bibliographic sources and meticulously analyzed. The project functional requirements are systematically analyzed. Despite the systematization of information, it must be remembered that the landscape is a concept as broad as integrator. Therefore, to improve the integration of industrial space in the landscape, we need an integrated approach that incorporates simultaneously all aspects of the design in all landscape scales. The realization of development must adapt and establish continuities with existing elements of the territory, as the structure of the plot, plants, historical traces, the urban fabric and infrastructure.

Industrial zones should not have areas with slopes more than 5\% and should suit the existing topography and establish continuities with adjacent crop terraces change (Fig. 2). As a general rule, it is preferable to adapt slopes to maintain the original morphology and use existing roads as access routes to prevent further soil disturbance and land use. The profile of the slopes should be adequate to ensure soil stability and to permit vegetation establishment.

Soil sealing should be minimum to decrease the negative effects on the environment and landscape. The industrial park should reduce soil occupation and

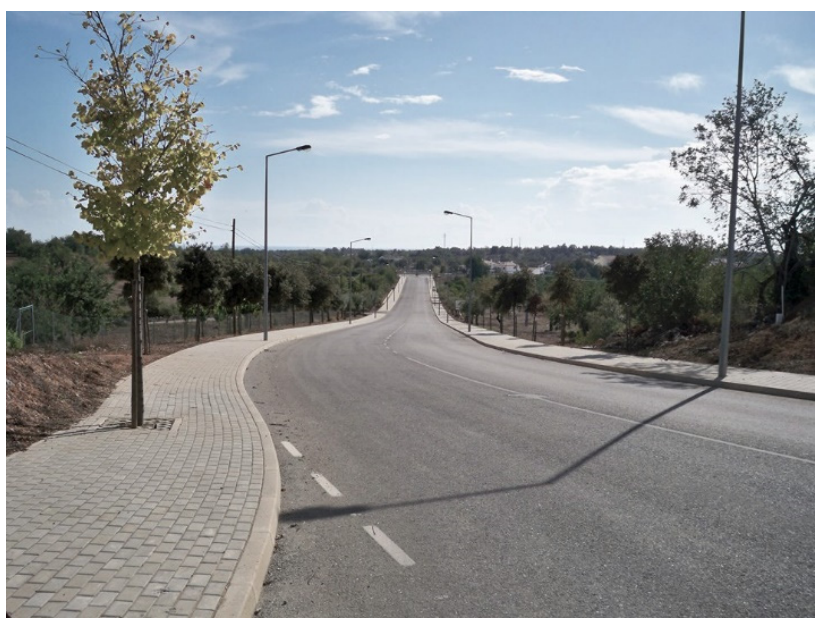

Figure 2: Integration of the new infrastructure to the existed landscape using design solution of native forest species and agriculture trees for coherent transition between land uses. 
promote green areas in a high percentage of the industrial land area. The Master Plan also need to delimit the areas of urbanization as close as possible to roads, so will minimize the impact and reduce fragmentation of the landscape. Relationships of permeability and symbiosis between the industrial and adjacent areas must be established to merge a complex network of relationships between the land uses and prevent functional separation of the territory. This can be achieved, for example, by placing green areas on the industrial fringe when in contact with residential areas to act as a filter, by creating green spaces of leisure as parks and gardens, by setting connections to nearby towns with bicycle lanes and public transport Planning and designing a strip of free built space in the perimeter, allows smooth contact with adjacent spaces and improve the external perception of the industrial site. The functions of this are diverse (recreation areas, visual filters, buffer zone to natural areas, production facilities like allotments, etc.). The areas reserved for protection (stream lines, infrastructure) are also areas of opportunity that may serve as transitional spaces and with adequate integration they may improve the landscape quality.

High visibility areas should set aside open space in order to reduce visual impact. Industrial buildings in plane areas should be joined with indigenous plants, making visual filters of ecotones. Structuring with right proportion of "empty" and "full" areas create a perception of overall quality and order. Always is preferable to order the building land with industrial volumes built homogeneous, continuous and compact, and prevent the construction of dispersed and highly varied volumes. The careful organization of the constructed volumes and the interposition of tree lines are mechanisms to create rhythms and to reduce visual disturbance. However, integration into the landscape structure based on the concealment and the interposition of visual barriers should be reserved only for extreme cases. The preferred strategy of integration should maintain relations with the visual environment to create a landscape unit, using resources such as vegetation and topography in order to harmonize them. The Master Plan should provide the location of large industry in the most visible part of the industrial park, because usually consists of isolated and unique type buildings, and this allows to form a more uniform overall picture. The location of the small industry, which often form a fragmented picture, should be placed in the less visible spaces.

The existing vegetation should be kept in mind in order to design new industrial areas. As general criteria, special attention should be given to the conservation of vegetation in surrounding areas. Species selection should privilege the use of native vegetation, without renouncing the utilization of exotic species with adaptation capacity to the site. Planting tree lines, shrubs and herbaceous vegetation is a useful strategy for achieving an impact on the degree visibility of the industrial area. Planting should be designed according to the desired effect, as far as proportion, rhythm, degree of transparency and color. However, in general, it is recommended to use native vegetation and use structures similar to nearby agricultural or natural plant formations. The use of vegetation on the perimeter must be particularly careful because it allows to establish relations with the environment, and it influences the perception of overall size. It is also an effective strategy to create a natural picture for the industrial-based elements [11] (fig. 3). 


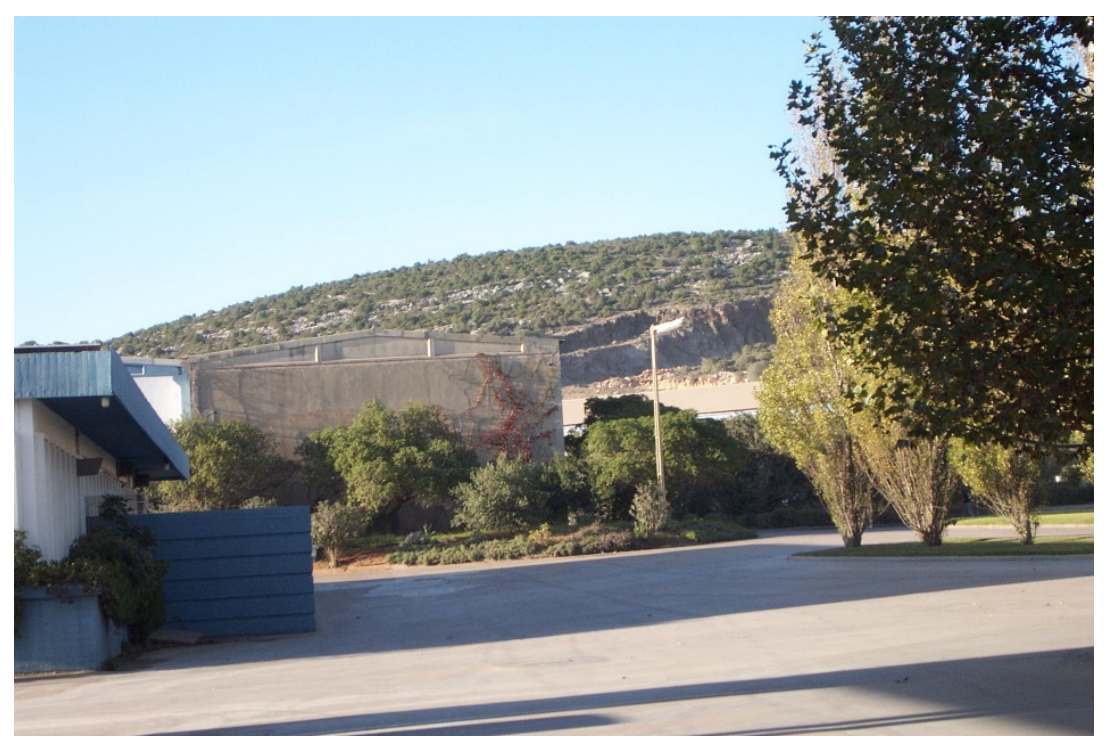

Figure 3: Proper use of vegetation contributes to hide the areas of volumetric industry and to establish a kind transition between the empty and full.

Colors and visual permeability are important factors for landscape integration of new industrial space. This does not mean higher costs but it requires some basic knowledge and sensitivity. Dark and opaque colors may have greatest impact on the buildings volume perception and seem heavier than lighter colors. Meanwhile, shiny surfaces must be avoided because of the produced reflexes, (especially the roofs should finish with less than $80 \%$ brightness). Using colors similar to the ground to ensure landscape integration.

Green spaces have to be planned as an integrated part of a system that includes roads and other elements of the industrial space. This means the spaces arranged according their functions and ensure the connection with main routes and strategic points (areas of services, bus stops, etc.). When inserted in an appropriate manner these areas have prominent structure and a significant ecological function.

The surrounding green areas may accommodate multiple uses while improving the relationship between industrial areas and its environment. Simple architectural compositions are functional and provide a sense of order and facilitate forming a harmonious ensemble. The architectural quality of the buildings is a key factor of the overall image of the spaces industry. Shapes, colors and textures columns and lighting must be consistent with the elements around them. It is better to opt for basic models and to facilitate their integration into a whole. Fences must have common characteristics in all industrial site. Open space equipment can set up a single or a range of models for different functional requirements, with a consistency of composition, color and materials with the other elements of the urbanization. Publicity of low dimensions and simple design may provide a discrete quality image throughout the industrial area. 


\section{Results and discussion}

\subsection{Concept and program}

For Schopenhauer [12], a great sense of beauty is to be obtained if the landscape expresses what he calls the 'idea', the essence of the place or perhaps its spirit (genius loci). Order and diversity are the necessary ingredients for an impulsive response to beauty, but the key ingredient in sustainable management of the landscapes is the knowledge of the essence of the place [13]. Meanwhile, what is essential in ecological sustainability is invisible to the eye of the public [14]. Thus, it is important to understand the role of place in achieving sustainable landscapes.

The concept that structures the proposal is the Eco-Industrial Park concept which is based on the principles of the industrial ecology, cleaner production and circular economy. Thus, in the industrial park of Santa Margarida we pretend combine nature, industry and society factors in order to realize a green and sustainable development [15]. The combination of these factors should respect the genius loci defined by Schopenhauer [12].

Based on an ecological vision it was identified the following design solutions that are presented in a master plan (fig. 4) that ensure the social needs for green infrastructure [16] of the workers and residents of this area and safeguard the resilience of the industrial park of Tavira. Moreover, the intervention program includes an urban square with shaded areas and a playground area and an urban allotment with a water recycled reservoir. These spaces are entirely related to the production, protection and recreation functions.

\subsection{Proposal}

The proposal was developed at the level of a conceptual Master Plan (Fig. 4). The sustainable techniques were proposed in order to not exceed the 1 million euro budget.

In particular, the Master Plan proposes the following issues that have translated into design solutions. A Multi-modal transportation system (walking, cycling, automobile, public transit) was planned (Fig. 5). In order to allow riding a bike in a safe way in all areas, a bike path should be implanted, $1.5 \mathrm{~km}$ long and 2 meters wide, with the purpose of the cyclist circulating in both traffic directions. In order to maintain the dimension of the pavement the bike path should occupy a portion of the existing road.

For the permeability of the soil and runoff reduction in the parking areas permeable pavements may be used for, such as grass grid so the water could infiltrate and decreases the risk of flooding.

The region of Algarve, and so the County of Tavira, receive very intensive solar radiation, for that reason, is a privileged place to reuse the solar energy. Solar car parks, solar benches, solar lights or solar panels in the top of the buildings, are some examples of the utilization of this sustainable technique.

Green walls can be used to decrease the visual and noise impact, and green roofs on buildings may provide multiple ecosystem services such as the reduction 


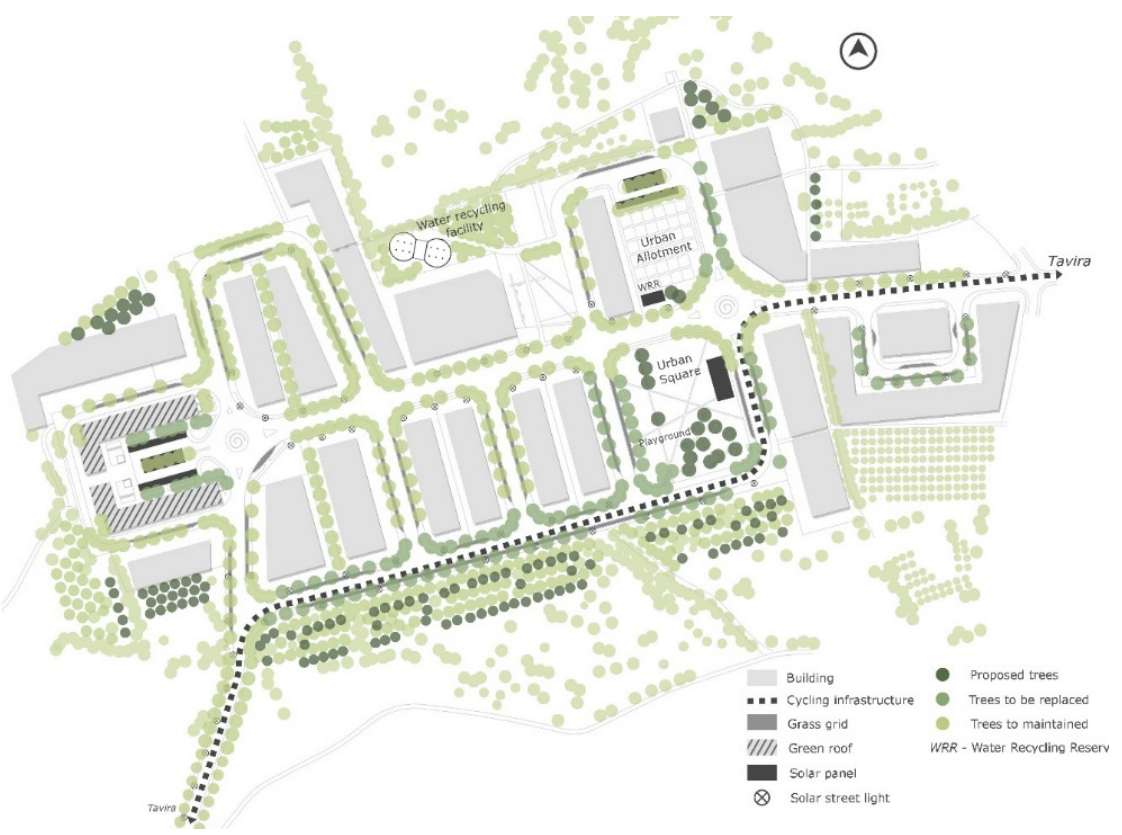

Figure 4: Master Plan of the Santa Margarida Eco-Industrial Park.

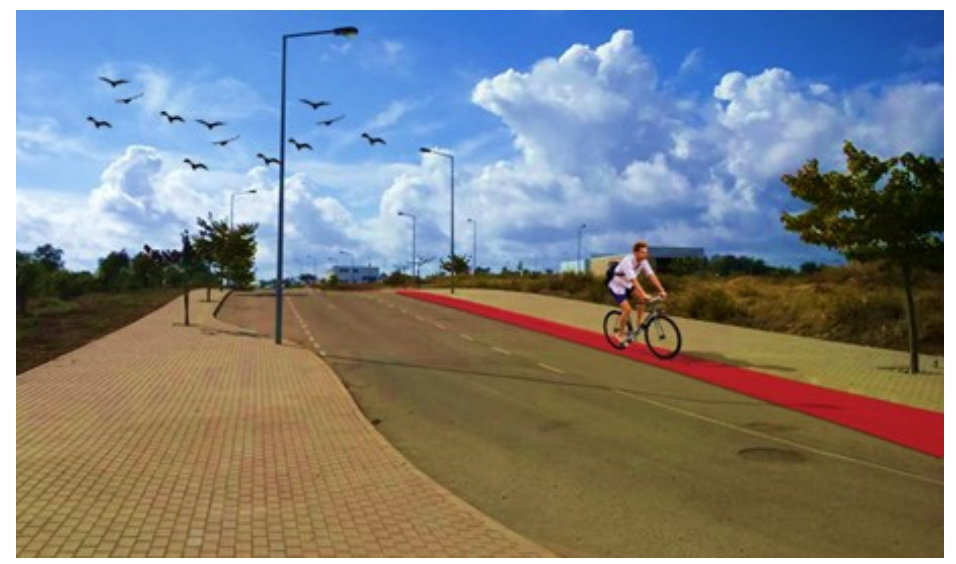

Figure 5: Promoting connections to nearby towns with bicycle lanes and public transport.

of heat loss from buildings in winter, cooling in the summer, retention of storm water and the provision of habitats. They may bring more and diverse natural features and processes into the urban area through locally adapted and resourceefficient interventions. However, the delivery of such services may be dependent on the characteristics of the plant species grown on them. 
As previously said, the area before the implementation of the Santa Margarida industrial park was characterized by a high quality rural landscape where there were numerous native species. So, with this intervention, we intend the substitution of all the invasive plants and some of the exotic plants by promotion of projects that use highly-adaptable plant species; trigger processes of selfpropagation of autochthonous species that require minimal maintenance interventions. For example, the Lantana camara, Erigeron karvinskianus and Pittosporum undulatum which are invasive plants in Portugal, may be replaced by Chamaerops humilis, Cistus albidus and Lavandula stoechas. Morus alba which is an exotic species with a high water requirement may be replaced by Celtis australis. These native species, in addition to being well adapted to the climatic conditions of the area and having an ornamental character, will be crucial to maintain the essence of the place or perhaps its genius loci [14].

\section{Conclusions}

In this paper, we demonstrate landscape integration of the infrastructures at the new industrial park of Tavira and application of sustainability techniques at the conceptual level Master Plan. We identify lessons for environmental management of similar industrial parks. Urban and industrial spaces planning should have a global and uniform treatment. Establishing sustainability techniques is an important way to serve the nearby affected communities who experience the impacts of development an industrial park in their neighborhood. Each part of the industrial area will benefit from the quality of the set and all elements. Even the smallest details are important in the formation of an industrial landscape quality. The compactness of the urbanized areas saves soil and facilitates the integration in the environment. Native vegetation is an excellent resource for landscape improvement with low maintenance. Sustainable landscape design in industrial environment are guaranteed quality and prestige living environment, healthy, stimulating and motivator. Investment in landscape improvements revert to the evaluation of enterprises in the industrial space and may lead to sustainable development.

Regional planners and policy, environmental management professionals who work with landscape integration of industrial parks are likely aware of these considerations. The current case study of eco-industrial park can be used as a 'living laboratory' for the development, deployment, testing and demonstration of replicable and locally adjusted sustainability techniques. The proposed solutions should be co-designed and co-implemented in a multi-stakeholder and participatory context. Thus, the following development phase of the Master Plan may undergo some changes due to the need for public hearing in a process of public participation. Methodologies to assess the efficacy, performance, and costeffectiveness of the sustainability techniques compared to alternative solutions will be also considered. 


\section{Acknowledgement}

The authors acknowledge the financial support given by the EU under Project INSPIRATION, H2020-SC5-2014-642372 and WARECAMO.

\section{References}

[1] Peddle MT. Planned industrial and commercial developments in the United States: a review of the history, literature and empirical evidence regarding industrial parks. Economic Development Quarterly, 7(1), pp. 107-124, 1993.

[2] Côté, R.P., Hall, J. Industrial parks as ecosystems. Journal of Cleaner Production, 3, pp. 41-46, 1995.

[3] Côté, R.P., Cohen-Rosenthal, E. Designing eco-industrial parks: a synthesis of some experiences. Journal of Cleaner Production, 6, pp. 181-188, 1998.

[4] Joss, S. Sustainable Cities: Governing for Urban Innovation. London: Palgrave Macmillan, 2015.

[5] Panagopoulos, T., Duque, J.A.G., Bostenaru Dan, M. Urban planning with respect to environmental quality and human well-being. Environmental Pollution, 208, pp. 137-144, 2016.

[6] Loures, L., Panagopoulos T. Reclamation of derelict industrial land in Portugal - greening is not enough. International Journal of Sustainable Development \& Planning, 5(4), pp. 343-350, 2010.

[7] Berte, E. Panagopoulos, T. Enhancing city resilience to climate change by means of ecosystem services improvement: A SWOT analysis for the city of Faro, Portugal. International Journal of Urban Sustainable Development, 6, pp. 241-253, 2014.

[8] Loures, L., Loures, A., Nunes, J., Panagopoulos, T. Landscape valuation of environmental amenities throughout the application of direct and indirect methods. Sustainability, 7, pp. 794-810, 2015.

[9] Environmental Impact Assessment of the Santa Margarida Industrial Area. NEMUS - Gestão e Requalificação Ambiental, Lda. Tavira, Portugal (last consulted 30-8-2016, http://siaia.apambiente.pt/AIADOC/AIA1054/ RNT1054.pdf)

[10] Guimaraes, M.E., Barreira, A.P., Panagopoulos, T. Shrinking Cities in Portugal - where and why. Revista Portuguesa de Estudos Regionais, 40, pp. 23-41, 2015.

[11] Buch, C.M. Guia d'integració paisatgística; Polígons industrials i sectors d'activitat econòmica. Catalunya Departament de Política Territorial i Obres Públiques, Barcelona, Spain, 2007.

[12] Schopenhauer, A. The World as a Will and Representation. Longman, New York, 1969.

[13] Bell, S. Can a fresh look at the psychology of perception and the philosophy of aesthetics contribute to the better management of forest landscapes? In: Sheppard, S.R.J., Harshaw, H.W. (Eds.), Forests and Landscapes: Linking 
Ecology, Sustainability and Aesthetics. CABI Publishing, Wallingford, United Kingdom, pp. 125-148, 2001.

[14] Panagopoulos T. Linking forestry, sustainability and aesthetics. Ecological Economics, 68, pp. 2485-2489, 2009.

[15] Luo, H., Meng, W., Ran, SH. Eco-industrial Park - theory and demonstration. Chemical Industry Press, Beijing, 2004.

[16] Karanikola, P., Tampakis, S., Panagopoulos, T., Karipidou-Kanari, A. Perceptions and expectations of urban green infrastructure in the municipality of Kalamaria, Greece. Management of Environmental Quality, 27(5), pp. 568-584, 2016.

[17] Loures, L., Panagopoulos, T., Burley, J.B. Assessing user preferences on Brownfield regeneration. The case of Arade river waterfront, South Portugal. Environment and Planning B: Planning and Design, 43(5), pp. 871-892, 2016. 